\title{
Crocetin Inhibits Lipopolysaccharide- Induced Inflammatory Response in Human Umbilical Vein Endothelial Cells
}

\author{
Lei Song ${ }^{a, b}$ Chen Kang ${ }^{a, c}$ Yuan Sun ${ }^{a, d}$ Wenrui Huang ${ }^{a, b} \quad$ Wei Liü,e Zhiyu Qian ${ }^{a}$ \\ aDepartment of Pharmacology, School of Pharmacy, China Pharmaceutical University, Nanjing, PR \\ China; ${ }^{b}$ Department of Molecular and Cellular Pharmacology, Miller School of Medicine, University \\ of Miami, Miami, FL, 'Division of Pharmacology, College of Pharmacy, Ohio State University, \\ Columbus, $\mathrm{OH}$, dDepartment of Chemistry and Biochemistry, Ohio State University, Columbus, $\mathrm{OH}$,

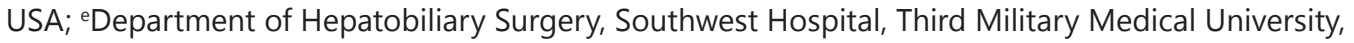 \\ Chongqing, PR China
}

\section{Key Words}

Crocetin $\bullet$ HUVEC $\cdot$ Vascular inflammation $\bullet \mathrm{MCP}-1 \cdot \mathrm{IL}-8 \cdot \mathrm{NF}-\mathrm{KB}$ p65

\begin{abstract}
Background/Aim: Crocetin is a readily bioavailable and bioactive compound extracted from Saffron. Previous studies indicated its various biomedical properties including antioxidant and anti-coagulation potencies. However, its effect on inflammation, notably within the cardiovascular system, has not been investigated yet. In the present study, we utilized human umbilical vein endothelial cell (HUVEC) to elucidate the effect of Crocetin on vascular inflammation. Methods: Cell viability and toxicity were evaluated by MTT and Lactate dehydrogenase (LDH) assay, respectively. Pro-inflammatory chemokine Monocyte Chemoattractant Protein-1 (MCP-1) and Interleukin-8 (IL-8) expressions were determined by RT-PCR and ELISA. With fluorescence labeled U937 cells, we examined immune cell adhesion to the inflamed HUVEC in vitro, which was further confirmed by the H\&E staining in the murine subcutaneous endothelium in vivo. Results: Upon Lipopolysaccharide (LPS)-induced inflammatory response in HUVECs, Crocetin ameliorated cell cytotoxicity, suppressed MCP-1 and IL-8 expressions through blocking NF-KB p65 signaling transduction. Moreover, Crocetin inhibited immune cells adhesion and infiltration to inflamed endothelium, which is a key step in inflammatory vascular injury. Conclusions: These findings suggest that Crocetin, a natural herb extract, is a potent suppressor of vascular endothelial inflammation.
\end{abstract}

\section{Introduction}

Crocetin is an ingredient originally discovered in dried stigma of Crocus Sativus (Saffron) [1], a herb served as traditional Chinese medicine over centuries. Recently, it draws attention in biomedical research due to Crocetin's ready bioavailability with few side effects. So far, 


\section{Cellular Physiology Cell Physiol Biochem 2016;40:443-452 \begin{tabular}{l|l|l} 
and BOI: 10.1159/000452559 & $\begin{array}{l}\text { C } 2016 \text { The Author(s). Published by S. Karger AG, Basel } \\
\text { www.karger.com/cpb }\end{array}$
\end{tabular} \\ Song et al.: Crocetin Regulates Endothelial Cell Inflammation in Hyperlipidemia}

accumulative evidence reveals its role on anti-cancer, anti-asthma, anti-oxidative stress, and anti-atherosclerosis [2-5].

Inflammation plays a critical role in cardiovascular disease (CVD) such as atherosclerosis [6-8]. Typically, during the initiation stage of atherogenesis, inflammation occurs in vascular endothelium, the innermost layer of the vessel. Inflamed endothelial cells release proinflammatory mediators, such as pro-inflammatory cytokines, chemokines, and adhesion molecules $[9,10]$. Recruited by these mediators, circulatory monocyte adheres to and infiltrate the lesion site, triggers subsequent pathogenesis process including excessive lipid accumulation, tunica smooth muscle cell migration, and plaque formation, results in amplification of vascular inflammation[6]. Two well-studied chemokines, MCP-1 and IL-8, are previously reported regulating immune cell adhesion, and integration with endothelial cell process [11-13], thus become potential therapeutic targets which attract research attention. Furthermore, production of those pro-inflammatory chemokines is mediated by transcription factor NF- $\mathrm{kB}$, an inflammatory-related signaling cascade which is activated during endothelium inflammation [14, 15]. So far, to our knowledge, Crocetin's antiinflammatory effect and its mechanism, have not been reported yet.

In present study, we aim to examine the therapeutic effect of Crocetin in vascular inflammation via its role in inhibition MCP-1 and IL-8. Of note, due to its high cost of Saffron, the fruit of Gardenia Jasminoides Ellis, a member of Rubiaceae family, is used as an alternative source for Crocetin extraction[16].

\section{Materials and Methods}

Preparation of Crocetin

Crocetin (>98\%, high-performance liquid chromatography, HPLC) was prepared by our group as previously described (Fig. 1)[16].

\section{Cell culture}

Human umbilical vein endothelial cell (HUVEC) line was generously offered by Dr. Vincent Moy (Miller School of Medicine, University of Miami); U937 human leukemic monocyte lymphoma cell line was purchased from Institution of Biochemistry and Cell Biology, SIBS (Shanghai, China). HUVECs were maintained in RPMI medium 1640 (GIBCO), and supplemented by Endothelial Cell Growth Kit (Lonza); U937 cells were grown in Dulbecco's modified Eagle's medium (DMEM, GIBCO) supplemented with 10\% fetal calf serum and 100 Unit/mL Penicillin and Streptomycin. A Trypan Blue (GIBCO) Staining was performed to guarantee $>95 \%$ live cells before experiments. Both cell lines were maintained in $5 \% \mathrm{CO}_{2}$ incubator at $37^{\circ} \mathrm{C}$.

\section{Cell viability assay}

HUVECs were seeded in 96-well plate at $1 \times 10^{4}$ cells/well. Cells were incubated in serum-deprived medium overnight, then exposed to Lipopolysaccharide (LPS, Sigma-Aldrich, $10 \mathrm{ng} / \mathrm{mL}$ ) with or without Crocetin $(1,5,10 \mathrm{ng} / \mathrm{mL})$ for $24 \mathrm{hr}$. Cell viability was measured by performing 3-(4, 5-dimethylthiazol-2yl)-2, 5- diphenyltetrazolium bromide (MTT, Sigma) assay as previously described[17].

Cell cytotoxicity assay

HUVECs were seeded in 12 well plate at $4 \times 10^{5}$ cells /well. Cells were incubated in serum-deprived medium overnight, then treated with LPS $(10 \mathrm{ng} / \mathrm{mL})$ with or without Crocetin $(1,5,10 \mathrm{ng} / \mathrm{mL})$ for $24 \mathrm{hr}$. After then, supernatants from each condition were harvested. Cell toxicity was determined by the lactate dehydrogenase (LDH) leakage into supernatant using LDH assay kit (JianCheng Bio-Technology Co. China) in accordance with manufacturer's instructions.

RNA isolation and reverse transcription-polymerase chain reaction (RT-PCR)

HUVECs were seeded in 6 well plate at $1.2 \times 10^{6}$ cells /well overnight, then treated with LPS (10 $\mathrm{ng} / \mathrm{mL})$ with or without Crocetin $(1,5,10 \mathrm{ng} / \mathrm{mL})$ for $24 \mathrm{hr}$. After that, total RNA was isolated by ZR RNA 


\section{Cellular Physiology Cell Physiol Biochem 2016;40:443-452 \begin{tabular}{l|l} 
and Biochemistry Published online: November 25, 2016 & $\begin{array}{l}\text { C } 2016 \text { The Author(s). Published by S. Karger AG, Basel } \\
\text { www.karger.com/cpb }\end{array}$
\end{tabular} \\ Song et al.: Crocetin Regulates Endothelial Cell Inflammation in Hyperlipidemia}

Fig. 1. Structural formula of Crocetin.

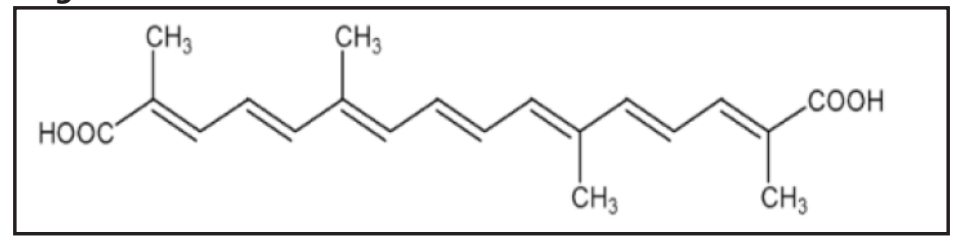

MiniPrep (Zymo Research) and reverse transcripted into cDNA by High capacity cDNA reverse transcription kit (Applied Biosystems) in accordance with manufacturer's instructions. Primers used for cDNA synthesis were as follow: MCP-1 (forward: 5' - AAG ATC TCA GTG CAG AGG CTC G-3'; reverse: 5'- CCA GGG GTA GAA CTG TGG TTC AA-3'); IL-8 (forward: 5'- TCT CAG CCC TCT TCA AAA ACT TCT C-3'; reverse: 5'-ATG ACT TCC AAG CTG GCC GTG GCT-3'); and housekeeping GAPDH (forward: 5'-CTC TCT GCT CCT CCT GTT CGA CAG-3'; reverse: 5'-GTG GAA TCA TAT TGG AAC ATG T-3'). PCR products were electrophoresed on 1.5\% agarose gel containing $0.1 \mu \mathrm{g} / \mathrm{mL}$ dye (Gold view, SBS Genetech Co. China). Gels were visualized and imaged by a GelDoc image analyzer (Bio-Rad); bands were quantified by ImageJ program.

Determination of MCP-1 and IL-8 by enzyme-linked immune sorbent assay (ELISA)

HUVECs were treated as previously described in 2.4 section. Cell culture supernatants from each condition were collected, filtered through a $0.45 \mu \mathrm{m}$ cell Nalgene syringe filter (Thermo Scientific) to remove the debris. Then ELISAs for MCP-1 and IL-8 (Bender) were performed according to manufacturer's instruction.

\section{Western blot}

HUVECs were treated as previously described in 2.5 section. The whole cell lysate was extracted by RIPA lysis buffer system (Santa Cruz Biotechnology); to separate the protein from the cytoplasm and nucleus, HUVECs were treated with a Nucleus and Cytoplasm protein extracting kit (KeyGEN, China), according to

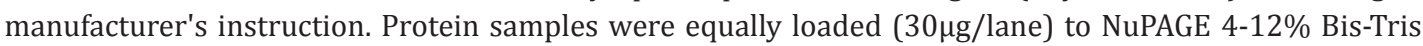
Gel (Novex, Life technologies) and resolved by electrophoresis, then transferred to polyvinylidene difluoride (PVDF, Millipore) membrane. The membrane was further incubated with antibodies against I $\kappa \mathrm{B} \alpha, \mathrm{NF}-\kappa \mathrm{B}$ p65 (Santa Cruz Biotechnology), or $\beta$-Actin (Sigma), followed by appropriate secondary antibodies incubation and ECL (Pierce) development. Immunoreactive bands were determined by Chemi-doc image analyzer (BioRad), and further analyzed by ImageJ program.

Cell adhesion assay

HUVECs were treated as previously described in 2.4 section. U937 cells were labeled with 2 ', $7{ }^{\prime}$-Bis(2-Carboxyethyl)-5-(and-6)-Carboxyfluorescein, Acetoxymethyl Ester (BCECF-AM, $3 \mu \mathrm{M}$ final concentration, Beyotime, China) for $30 \mathrm{~min}$ at $37^{\circ} \mathrm{C}$, re-suspended in serum-free medium. Labeled U937 cells $\left(5 \times 10^{4}\right.$ cell/ $\mathrm{mL}$ ) were equally distributed into each well co-culture with HUVECs for $2 \mathrm{hr}$ at $37^{\circ} \mathrm{C}$. After $2 \mathrm{hr}$ incubation, the supernatant was removed by gentle aspiration; wells were washed with warm PBS for 3 times. U937 cells bound to HUVECs were fixed with 4\% paraformaldehyde in PBS, fluorescence was observed at 485nm excitation and 530nm emission wavelength. Images were further quantified and analyzed by ImageJ program.

\section{Histological examination}

Male Sprague-Dawley rats were kept under standard housing conditions. Rats received LPS (0.5 $\mathrm{mg} / \mathrm{kg}$ ) injection subcutaneously in the abdomen with or without oral administration of Crocetin (25, $50,100 \mathrm{mg} / \mathrm{kg}$ ) twice a day for consecutive three days. Animals were sacrificed $24 \mathrm{hr}$ after the last drug administration. Subcutaneous tissues were harvested, fixed in $10 \%$ buffered formalin and then embedded in paraffin for $\mathrm{H} \& \mathrm{E}$ staining.

Statistical analysis

Data were presented as mean \pm S.E.M. One way ANOVA followed by Newman-Keuls test was applied for statistical analysis. A $p<0.05^{*}$ or $p<0.01 * *$ was considered as significant. 


\section{Cellular Physiology Cell Physiol Biochem 2016;40:443-452 \begin{tabular}{l|l} 
and Biochemistry & DOI: 10.1159/000452559 \\
Published online: Nove 2016 The Author(s). Published by S. Karger AG, Basel
\end{tabular} \\ Song et al.: Crocetin Regulates Endothelial Cell Inflammation in Hyperlipidemia}

\section{Results}

\section{LPS-induced cell death is alleviated by Crocetin treatment}

HUVECs displayed decreased cell viability following 24hr LPS stimulation (Fig. 2), MTT assay was used to determine if Crocetin could alleviate this LPS-induced cell damage and cell death. Cell viability was normalized to the untreated group and expressed as the percentage (control group considered as 100\% viability). As shown in Fig. 2A, elevated cell viability was achieved with a high dose Crocetin treatment $(p<0.05)$ compared to Model (LPS only) group. Although no significant viability change was observed in Crocetin treatment alone at given doses (Fig. 2B).

\section{Crocetin inhibits LPS-induced cytotoxicity}

Lactate dehydrogenase ( $\mathrm{LDH}$ ), as an inflammatory biomarker, is prevalently used to evaluate cell inflammation and tissue damage. Our previous study suggested that Crocetin suppresses LPS-induced cell death, and in this study, we further investigated Crocetin's effect on decreasing LPS-induced cytotoxicity. HUVECs were treated for $24 \mathrm{hr}$ with LPS and Crocetin of different doses. LDH leakage level in the supernatant was elevated in Model (LPS only) group compared to untreated group $(p<0.05)$. As expected, LDH elevation in the Model (LPS only) group was suppressed with Crocetin treatment in a dose-dependent manner (Fig. $3, p<0.05$ or $p<0.01$ ), indicating the protective role of Crocetin on HUVECs inflammatory response.

A

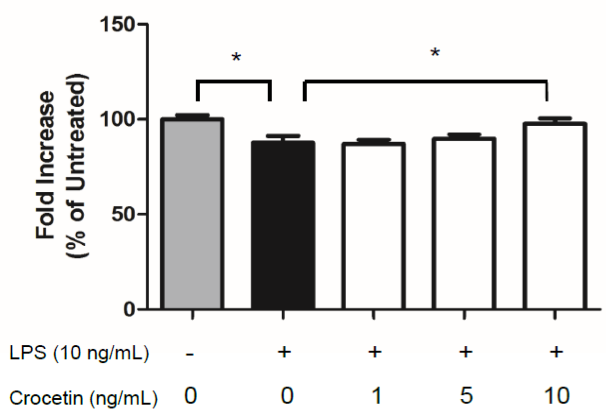

B

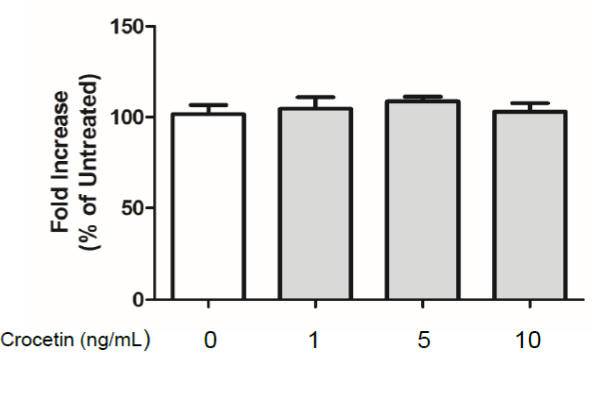

Fig. 2. (A) Effect of Crocetin on cell viability. HUVECs were exposed to LPS ( $10 \mathrm{ng} / \mathrm{mL}$ ) while treated with or without Crocetin at concentration of $1,5,10 \mathrm{ng} / \mathrm{mL}$ for $24 \mathrm{hr}$. The cell viability was measured by MTT assay. (B) Effect of Crocetin on cell viability. HUVECs were treated with Crocetin at different doses (0, 1, 5, $10 \mathrm{ng} /$ $\mathrm{mL}$ ) for $24 \mathrm{hr}$. Cell viability was measured by MTT assay. Values were expressed as mean \pm S.E.M from three independent experiments. * indicates $p<0.05$.

Fig. 3. Effect of Crocetin on LPS induced cytotoxicity. HUVECs were exposed to LPS $(10 \mathrm{ng} / \mathrm{mL})$ while treated with or without Crocetin $(1,5,10 \mathrm{ng} / \mathrm{mL})$ for $24 \mathrm{hr}$. Supernatants were collected for LDH leakage determination. Data were expressed as the mean \pm S.E.M of the results from three independent experiments. * indicates $p<0.05$; ** indicates $p<0.01$.

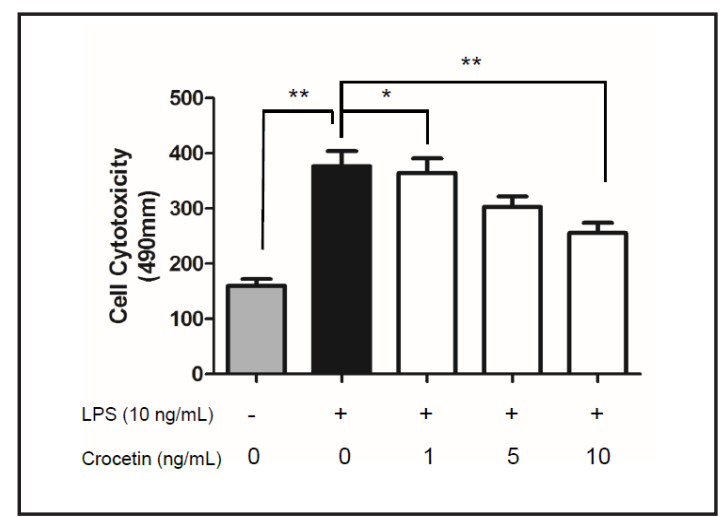


Fig. 4. Crocetin's effect on MCP-1 and IL-8 mRNA expression levels. HUVECs were exposed to LPS (10 ng/ $\mathrm{mL}$ ) while treated with or without Crocetin (1, 5, $10 \mathrm{ng} / \mathrm{mL}$ ) for $24 \mathrm{hr}$. The mRNA levels of MCP-1 and IL-8 were determined by RT-PCR. Data were expressed as the mean \pm S.E.M of the results from three separate experiments. ** indicates $p<0.01$.
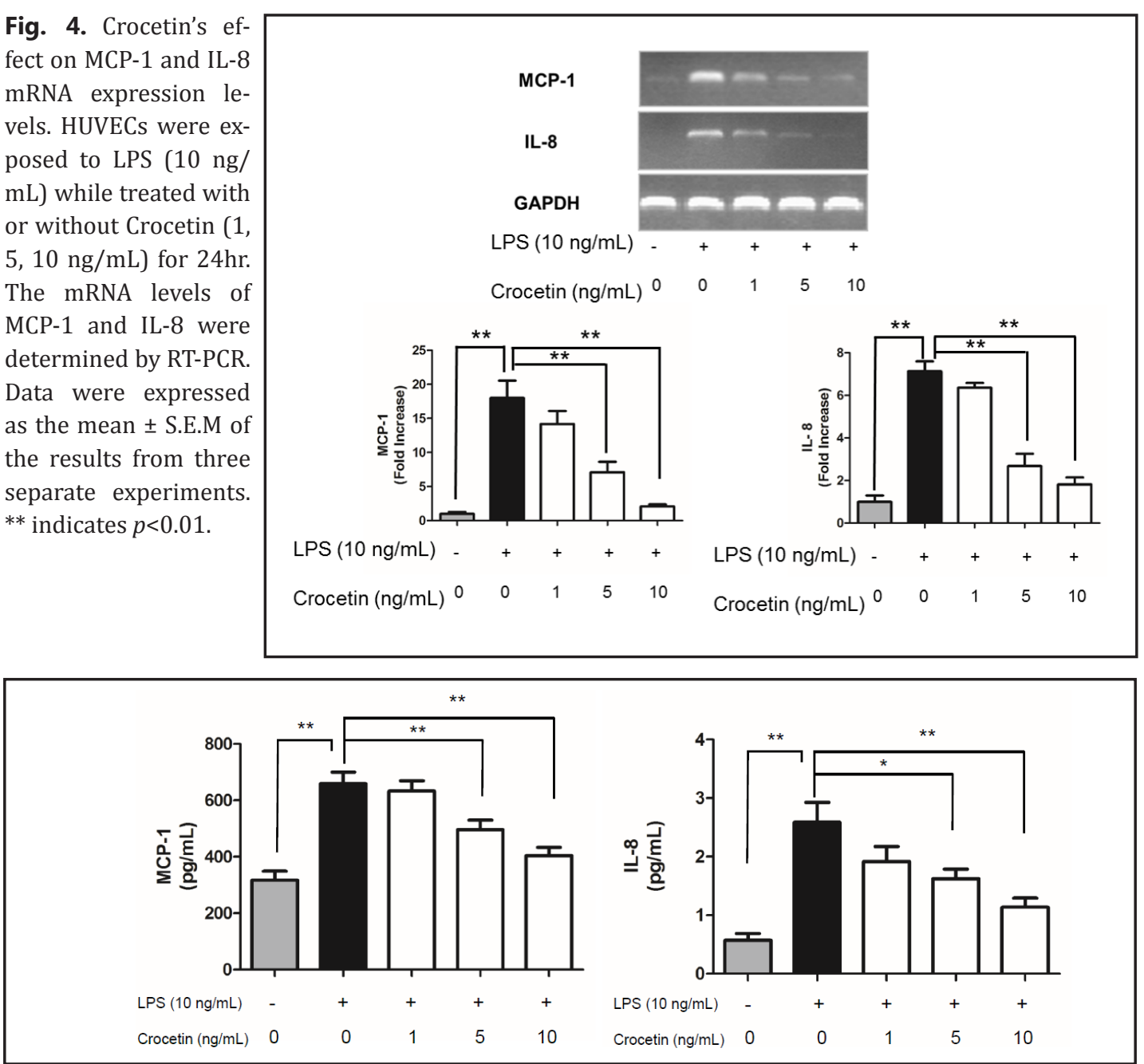

Fig. 5. Crocetin's effect on MCP-1 (A) and IL-8 (B) secretions by ELISA. HUVECs were exposed to LPS (10 $\mathrm{ng} / \mathrm{mL}$ ) while treated with or without Crocetin $(1,5,10 \mathrm{ng} / \mathrm{mL})$ for $24 \mathrm{hr}$. Supernatants were collected to determine MCP-1 and IL-8 levels by ELISA. Data were expressed as the mean \pm S.E.M of the results from three separate experiments. * indicates $p<0.01$; ** indicates $p<0.01$.

Elevated expression of chemokine MCP-1 and IL-8 is abrogated by Crocetin

MCP-1 and IL-8 are important pro-inflammatory chemokines involved in vascular inflammatory response and regulate immune cell migration to the lesion site. To understand Crocetin's role in inhibiting LPS induced MCP-1 and IL-8 expression and secretion, RT-PCR and ELISA were performed respectively. As in Fig. 4, MCP-1 and IL-8 gene expression levels were significantly increased with LPS stimulation. However, this elevation was abrogated by Crocetin treatment, in a dose dependent manner $(p<0.01)$. Furthermore, to confirm Crocetin's effect on MCP-1 and IL- 8 secretions, the cell supernatants were collected for ELISA. In accordance with the RT-PCR results, MCP-1 (Fig. 5A) and IL-8 (Fig. 5B) secretions were both increased by LPS stimulation $(p<0.01)$ and subsequently decreased by Crocetin treatment at different doses as expected $(p<0.05$ or $p<0.01)$.

\section{Inflammatory cell adhesion and infiltration are alleviated by Crocetin treatment}

In the aforementioned results, both chemokine MCP-1 and IL-8 levels were significantly elevated induced by LPS, while alleviated by Crocetin treatment. Based on the known role of MCP-1 and IL-8 in cell migration and adhesion, a functional assay was performed to investigate if Crocetin can block immune cell adhesion to the inflamed HUVECs. As indicated 


\section{Cellular Physiology Cell Physiol Biochem 2016;40:443-452

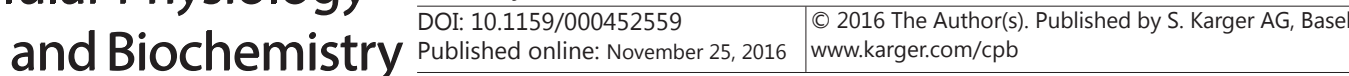

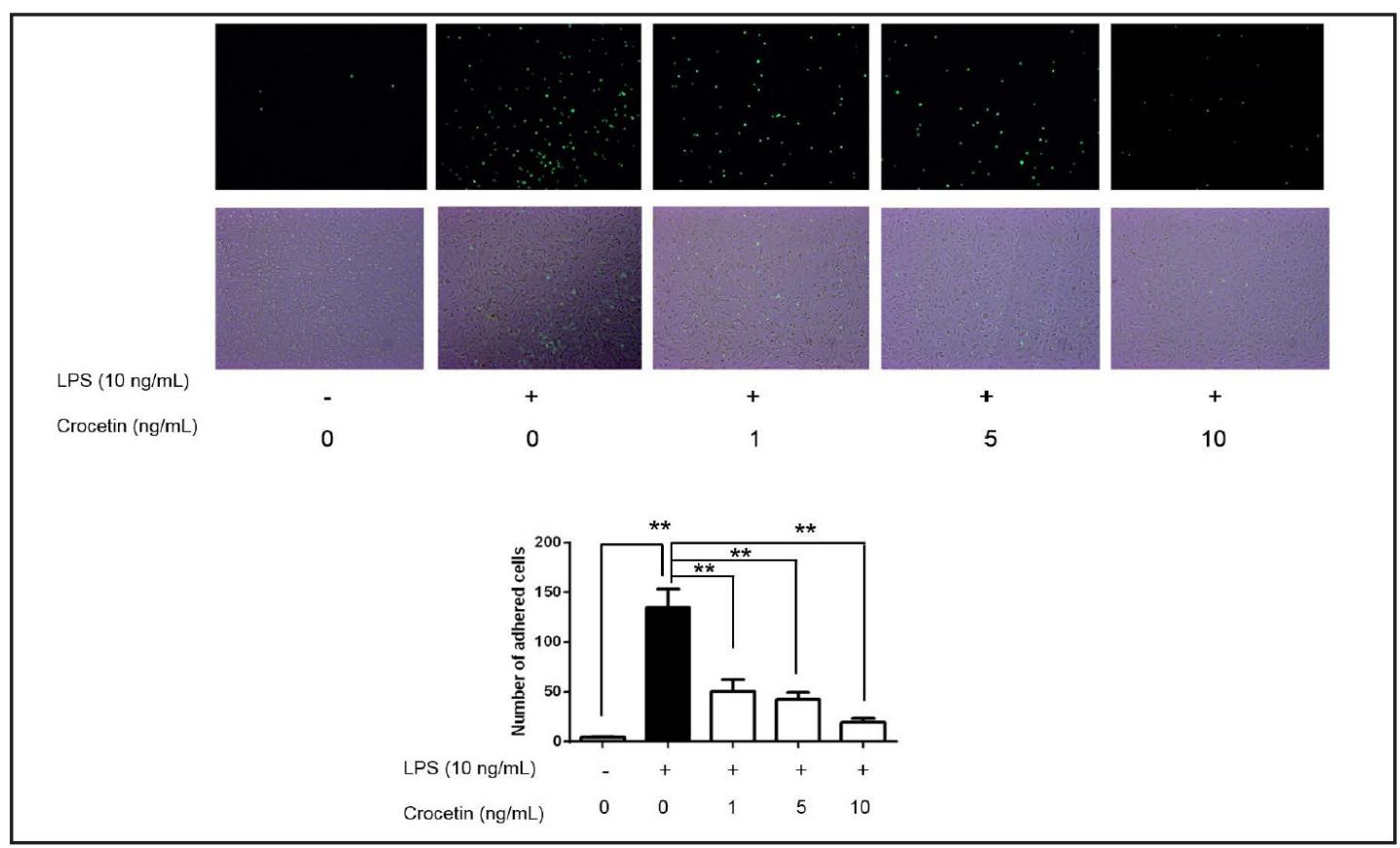

Fig. 6. Crocetin's effect on U937 cell adhesion to HUVECs. HUVECs were exposed to LPS (10 ng/mL) while treated with or without Crocetin (1,5,10 ng/mL) for $24 \mathrm{hr}$, then co-cultured with fluorescently labelled U937 cells for $2 \mathrm{hr}$, after which they were fixed and imaged by fluorescence microscopy. ${ }^{* *}$ indicates $p<0.01$.

Fig. 7. Crocetin's effect on immune cell adhesion and infiltration in vivo. Rats were received a subcutaneous injection on the abdomen with LPS $(0.5$ $\mathrm{mg} / \mathrm{kg}$ ) for 1 time and oral administration of Crocetin (25, $50,100 \mathrm{mg} / \mathrm{kg}$ ) twice a day for three days. $24 \mathrm{hr}$ after the last drug administration, rats were sacrificed. Subcutaneous tissues were harvested, fixed in $10 \%$ buffered formalin and embedded in paraffin for H\&E staining.

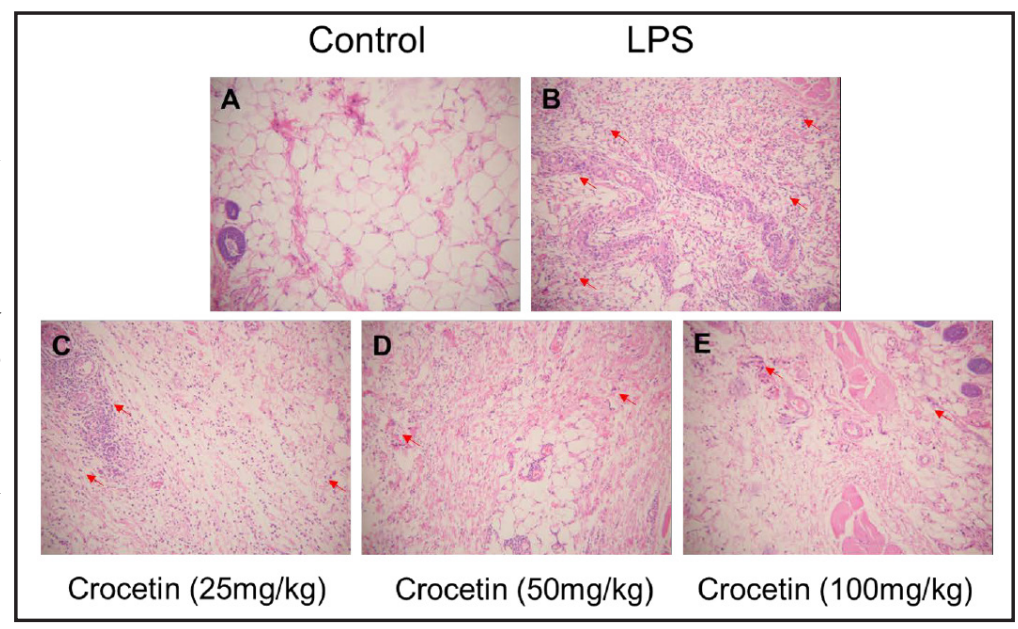

in Fig. 6, U937, human leukemic monocyte lymphoma cells were fluorescently labeled, then co-cultured with HUVECs for $2 \mathrm{hr}$ at $37^{\circ} \mathrm{C}$. In accordance with secreting MCP-1 and IL-8 level, LPS and Crocetin co-treated groups displayed a significantly lower number of adhered U937 ( $p<0.01$ ) compared to Model (LPS only) group, indicating U937 adhesion to inflamed HUVECs was abrogated. This result was further confirmed by H\&E staining in murine subcutaneous endothelium in Fig. 7. LPS induced massive inflammatory cell infiltration with disarranged endothelium structure (Fig. 7B). However, Crocetin treatment markedly attenuated cell infiltration in a dose-dependent manner (Fig. 7C, D, and E). Moreover, the restored endothelial structure was observed in Crocetin treated groups (Fig. 7D and E).

Crocetin exerts its anti-inflammatory effect through suppression NF- $\mathrm{KB}$ p 65 transduction

Knowing that Crocetin downregulates LPS-induced MCP-1 and IL-8 expression, we next sought to study potential signaling pathway that Crocetin may affect. NF-kB, known as a 
Fig. 8. Effect of Crocetin on NF- $\kappa B$ signaling inhibition. HUVECs were exposed to LPS (10 ng/mL) while treated with or without Crocetin $(1,5,10 \mathrm{ng} / \mathrm{mL})$ for $24 \mathrm{hr}$. Cytosolic and nuclear fractions were prepared and resolved by SDS-PAGE. IкB- $\alpha$ (A) NF- $\kappa B$ p65 (B, cytosolic extraction; $\mathrm{C}$, nuclear extraction) and were detected by western blot. $\beta$-Actin was used as loading control. Data were expressed as the mean \pm S.E.M of three individual experiments. * indicates $p<0.05$; ** indicates $p<0.01$.

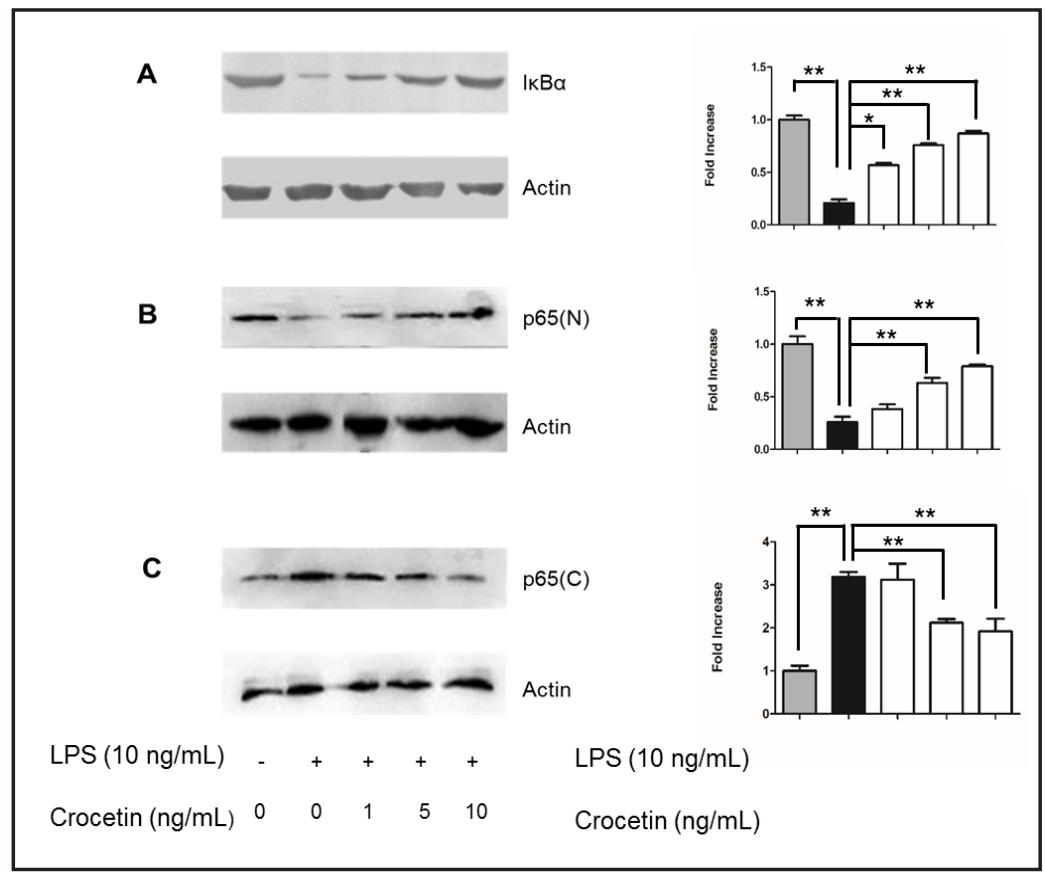

classic inflammation related signal pathway, is widely activated in inflammatory processes in different cell types. Upon NF-кB signaling activation, ІкВ kinase (IKK) is recruited to phosphorylate its substrate IкB $\alpha$. Associated with phosphorylation and degradation of $\mathrm{IkB} \alpha$, the p65 subunit will be released from the IкB $\alpha$-p65-p50 complex, and translocate into the nucleus. As a result, the transcriptional activity of many pro-inflammatory cytokines and chemokines including IL-8 and MCP-1 will be triggered and elevated. According to our findings, LPS-induced IKB $\alpha$ degradation was observed (Fig. 8A), associated with NF-kB p65 translocation. This translocation manifests as decreased p65 level in the cytoplasm and concurrently increased level in the nucleus (Fig. 8B, C). However, Crocetin stabilizes $\mathrm{IkB} \alpha$ subunit and therefore, abrogates p65 translocation, inhibiting downstream proinflammatory cytokines and chemokines transcriptional activities.

\section{Discussion}

In this study, endotoxin Lipopolysaccharide (LPS) was used to induce the endothelial inflammatory response in HUVECs. As an exogenous stimulus, LPS has been widely used in endothelium damage and repair studies, due to its character of increasing cell permeability and impairing endothelium barrier, which is an essential step in inflammation initiation stage $[18,19]$. This stress-induced cell death and cytotoxicity were determined by MTT assay (Fig. 2), and LDH leakage assay (Fig. 3), respectively. These indicators of inflammatory stress decreased under Crocetin treatment in a dose-dependent manner, indicating higher cell viability and lower LDH leakage. Also, our studies confirmed elevated levels of proinflammatory, and adhesion related chemokines MCP-1 and IL-8 under LPS stimulation in HUVECs. These induced effects were observed in both transcription and translation levels, which could be subsequently ameliorated by Crocetin treatment in a dose-dependent manner (Fig. 4, 5).

In CVDs such as atherosclerosis, inflammation is initiated by immune cell adhesion to endothelium [20], which may trigger a positive pro-inflammatory feedback loop, and further, amplify inflammation [21]. Thus, the inhibition of cell adhesion is promising for CVDs treatment. To explore this inhibition activity by Crocetin, a cell adhesion assay, which compares the physiological and pathological (inflammatory) vascular conditions [22, 23], 


\section{Cellular Physiology Cell Physiol Biochem 2016;40:443-452

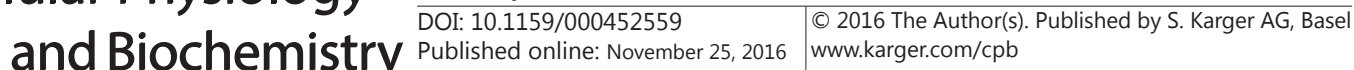 \\ Song et al.: Crocetin Regulates Endothelial Cell Inflammation in Hyperlipidemia}

in MCP-1 and IL-8 was performed. The Crocetin-mediated inhibition was observed in monocyte adhesion to endothelial cells (Fig. 6). Moreover, Crocetin treatment was able to restore subcutaneous endothelium structure, as well as to alleviate immune cell infiltration to lesion site compared to the LPS treated group (Fig. 7).

Multiple pathways are proposed in the vascular injury and its inflammatory process according to growing evidence, including eNOS/PI3K/Akt [24], mitogen-activated protein kinase (MAPK) [25-27], transforming growth factor - $\beta$ (TGF- $\beta$ ) [28], and NF-kB signaling [29]. The inhibitory effect of Crocetin on MAPKs including ERK1/2, p38, and JNK has been widely studied and reported. However, Crocetin's effect on NF-kB during vascular inflammation needs further investigation. As a key nuclear transcription factor, the NF-kB pathway can be activated by factors such as bacterial endotoxin [30], inflammatory pharmacological agents, and $\mathrm{T}$ cell mitogens. Specifically, previous studies indicated it is mediated by upstream regulator toll-like receptor (TLR) family, especially TLR4. As a ligand of TLR[31], we applied LPS stimulation to activate IKB $\alpha$ kinase (IKK) via tumor necrosis factor receptor (TNFR), and interleukin-1 receptor (IL-1R), which further phosphorylates and signals for degrading the

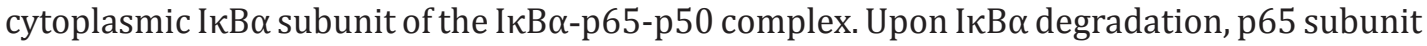
is released and translocated into the nucleus, where it activates downstream inflammatory gene translational activity. Crocetin was observed to stabilize the IкB $\alpha-p 65-p 50$ complex, thereby blocking its signaling cascade (Fig. 8). These indicate that Crocetin achieves its antiinflammatory activity via NF-kB signaling pathway. This novel mechanism may contribute further understanding of NF-kB's activation in cardiovascular disease, and opens up a new direction of Crocetin treatment in CVDs.

In conclusion, we demonstrated the efficacy of Crocetin in alleviating the inflammatory response stimulated by LPS in HUVECs. This stimulated inflammatory process is linked with CVD inflammation, which may also involve in diabetes, hypertension, and cancer [32-35]. Our study further supports Crocetin as a strong candidate anti-inflammatory drug with few side effects. Crocetin's potential clinical value may thus go beyond CVDs, and be applied in a wider range of inflammation related diseases.

\section{Acknowledgements}

Authors thank Department of Pathology, Nanjing Medical University for H\&E staining assistance. Also, authors would like to thank Dr. Vincent Moy for generously providing HUVEC cell line and Ru Wen for critical reading of this manuscript.

\section{Disclosure Statement}

Authors declare no conflict of interest.

\section{References}

1 Heriberto Caballero-Ortegaa RP-M, Fikrat I. Abdullaev: HPLC quantification of major active components from 11 different saffron (Crocus sativus L.) sources. Food Chemistry 2005;100:1126-1131.

2 Bathaie SZ, Hoshyar R, Miri H, Sadeghizadeh M: Anticancer effects of crocetin in both human adenocarcinoma gastric cancer cells and rat model of gastric cancer. Biochem Cell Biol 2013;91:397-403.

3 Yoshino F, Yoshida A, Umigai N, Kubo K, Lee MC: Crocetin reduces the oxidative stress induced reactive oxygen species in the stroke-prone spontaneously hypertensive rats (SHRSPs) brain. J Clin Biochem Nutr 2011;49:182-187.

4 Zheng S, Qian Z, Tang F, Sheng L: Suppression of vascular cell adhesion molecule-1 expression by crocetin contributes to attenuation of atherosclerosis in hypercholesterolemic rabbits. Biochem Pharmacol 2005;70:1192-1199. 


\section{Cellular Physiology Cell Physiol Biochem 2016;40:443-452 and Biochemistry Published online: November 25, 2016 \begin{tabular}{l|l} 
DOI: 10.1159/000452559 & $\begin{array}{l}\text { C } 2016 \text { The Author(s). Published by S. Karger AG, Basel } \\
\text { www.karger.com/cpb }\end{array}$
\end{tabular} \\ Song et al.: Crocetin Regulates Endothelial Cell Inflammation in Hyperlipidemia}

5 Ding J, Su J, Zhang L, Ma J: Crocetin Activates Foxp3 Through TIPE2 in Asthma-Associated Treg Cells. Cell Physiol Biochem 2015;37:2425-2433.

6 Halvorsen B, Smedbakken LM, Michelsen AE, Skjelland M, Bjerkeli V, Sagen EL, Tasken K, Bendz B, Gullestad L, Holm S, Biessen EA, Aukrust P: Activated platelets promote increased monocyte expression of CXCR5 through prostaglandin E2-related mechanisms and enhance the anti-inflammatory effects of CXCL13. Atherosclerosis 2014;234:352-359.

7 Frangogiannis NG: Regulation of the inflammatory response in cardiac repair. Circ Res 2012;110:159-173.

8 Halmer R, Davies L, Liu Y, Fassbender K, Walter S: The Innate Immune Receptor CD14 Mediates Lymphocyte Migration in EAE. Cell Physiol Biochem 2015;37:269-275.

9 Meng G, Liu Y, Lou C, Yang H: Emodin suppresses lipopolysaccharide-induced pro-inflammatory responses and NF-kappaB activation by disrupting lipid rafts in CD14-negative endothelial cells. Br J Pharmacol 2010;161:1628-1644.

10 Zeng XK, Guan YF, Remick DG, Wang X: Signal pathways underlying homocysteine-induced production of MCP-1 and IL-8 in cultured human whole blood. Acta Pharmacol Sin 2005;26:85-91.

11 Goser S, Ottl R, Brodner A, Dengler TJ, Torzewski J, Egashira K, Rose NR, Katus HA, Kaya Z: Critical role for monocyte chemoattractant protein-1 and macrophage inflammatory protein-1alpha in induction of experimental autoimmune myocarditis and effective anti-monocyte chemoattractant protein-1 gene therapy. Circulation 2005;112:3400-3407.

12 Smith WB, Gamble JR, Clark-Lewis I, Vadas MA: Interleukin-8 induces neutrophil transendothelial migration. Immunology 1991;72:65-72.

13 Soehnlein 0, Lindbom L, Weber C: Mechanisms underlying neutrophil-mediated monocyte recruitment. Blood 2009;114:4613-4623.

14 Hipp MS, Urbich C, Mayer P, Wischhusen J, Weller M, Kracht M, Spyridopoulos I: Proteasome inhibition leads to NF-kappaB-independent IL-8 transactivation in human endothelial cells through induction of AP1. Eur J Immunol 2002;32:2208-2217.

15 Goebeler M, Gillitzer R, Kilian K, Utzel K, Brocker EB, Rapp UR, Ludwig S: Multiple signaling pathways regulate NF-kappaB-dependent transcription of the monocyte chemoattractant protein-1 gene in primary endothelial cells. Blood 2001;97:46-55.

16 Xi L, Qian Z, Shen X, Wen N, Zhang Y: Crocetin prevents dexamethasone-induced insulin resistance in rats. Planta Med 2005;71:917-922.

17 Kim EJ, Park WH, Ahn SG, Yoon JH, Kim SW, Kim SA: 5'-nitro-indirubinoxime inhibits inflammatory response in TNF-alpha stimulated human umbilical vein endothelial cells. Atherosclerosis 2010;211:77-83.

18 Yin X, Liang Z, Yun Y, Pei L: Intravenous Transplantation of BMP2-Transduced Endothelial Progenitor Cells Attenuates Lipopolysaccharide-Induced Acute Lung Injury in Rats. Cell Physiol Biochem 2015;35:21492158.

19 Uhlig S, Yang Y, Waade J, Wittenberg C, Babendreyer A, Kuebler WM: Differential regulation of lung endothelial permeability in vitro and in situ. Cell Physiol Biochem 2014;34:1-19.

20 O'Brien KD, Allen MD, McDonald TO, Chait A, Harlan JM, Fishbein D, McCarty J, Ferguson M, Hudkins K, Benjamin CD, et al.: Vascular cell adhesion molecule-1 is expressed in human coronary atherosclerotic plaques. Implications for the mode of progression of advanced coronary atherosclerosis. J Clin Invest 1993;92:945-951.

21 Ghigo A, Franco I, Morello F, Hirsch E: Myocyte signalling in leucocyte recruitment to the heart. Cardiovasc Res 2014;10.1093/cvr/cvu030

22 Gerszten RE, Garcia-Zepeda EA, Lim YC, Yoshida M, Ding HA, Gimbrone MA, Jr., Luster AD, Luscinskas FW, Rosenzweig A: MCP-1 and IL-8 trigger firm adhesion of monocytes to vascular endothelium under flow conditions. Nature 1999;398:718-723.

23 Papadopoulou C, Corrigall V, Taylor PR, Poston RN: The role of the chemokines MCP-1, GRO-alpha, IL-8 and their receptors in the adhesion of monocytic cells to human atherosclerotic plaques. Cytokine 2008;43:181-186.

24 Dong R, Chen W, Feng W, Xia C, Hu D, Zhang Y, Yang Y, Wang DW, Xu X, Tu L: Exogenous Bradykinin Inhibits Tissue Factor Induction and Deep Vein Thrombosis via Activating the eNOS/Phosphoinositide 3-Kinase/ Akt Signaling Pathway. Cell Physiol Biochem 2015;37:1592-1606. 


\section{Cellular Physiology Cell Physiol Biochem 2016;40:443-452 \begin{tabular}{l|l|l} 
DOI: 10.1159/000452559 & $\begin{array}{l}\text { O 2016 The Author(s). Published by S. Karger AG, Basel } \\
\text { www.karger.com/cpb }\end{array}$
\end{tabular} \\ Song et al.: Crocetin Regulates Endothelial Cell Inflammation in Hyperlipidemia}

25 Patel DN, King CA, Bailey SR, Holt JW, Venkatachalam K, Agrawal A, Valente AJ, Chandrasekar B: Interleukin-17 stimulates C-reactive protein expression in hepatocytes and smooth muscle cells via p38 MAPK and ERK1/2-dependent NF-kappaB and C/EBPbeta activation. J Biol Chem 2007;282:27229-27238.

26 Silverstein RL: Inflammation, atherosclerosis, and arterial thrombosis: role of the scavenger receptor CD36. Cleve Clin J Med 2009;76:S27-30.

27 Saklatvala J: The p38 MAP kinase pathway as a therapeutic target in inflammatory disease. Curr Opin Pharmacol 2004;4:372-377.

28 Robertson AK, Rudling M, Zhou X, Gorelik L, Flavell RA, Hansson GK: Disruption of TGF-beta signaling in T cells accelerates atherosclerosis. J Clin Invest 2003;112:1342-1350.

29 Yang R, Yang L, Shen X, Cheng W, Zhao B, Ali KH, Qian Z, Ji H: Suppression of NF-kappaB pathway by crocetin contributes to attenuation of lipopolysaccharide-induced acute lung injury in mice. Eur J Pharmacol 2012;674:391-396.

30 Kim JY, Park SJ, Yun KJ, Cho YW, Park HJ, Lee KT: Isoliquiritigenin isolated from the roots of Glycyrrhiza uralensis inhibits LPS-induced iNOS and COX-2 expression via the attenuation of NF-kappaB in RAW 264.7 macrophages. Eur J Pharmacol 2008;584:175-184.

31 Shirasuna K, Shimamura N, Seno K, Ohtsu A, Shiratsuki S, Ohkuchi A, Suzuki H, Matsubara S, Nagayama S, Iwata H, Kuwayama T: Moderate Hypoxia Down-Regulates Interleukin-6 Secretion and TLR4 Expression in Human Sw.71 Placental Cells. Cell Physiol Biochem 2015;36:2149-2160.

32 Rana JS, Nieuwdorp M, Jukema JW, Kastelein JJ: Cardiovascular metabolic syndrome - an interplay of, obesity, inflammation, diabetes and coronary heart disease. Diabetes Obes Metab 2007;9:218-232.

33 Lutsey PL, Jacobs DR, Jr., Kori S, Mayer-Davis E, Shea S, Steffen LM, Szklo M, Tracy R: Whole grain intake and its cross-sectional association with obesity, insulin resistance, inflammation, diabetes and subclinical CVD: The MESA Study. Br J Nutr 2007;98:397-405.

34 Mathieu P, Poirier P, Pibarot P, Lemieux I, Despres JP: Visceral obesity: the link among inflammation, hypertension, and cardiovascular disease. Hypertension 2009;53:577-584.

35 Hofseth LJ, Wargovich MJ: Inflammation, cancer, and targets of ginseng. J Nutr 2007;137:183S-185S. 